\title{
Inclusion and its practices: socio-anthropological aspects of the production of Deaf-inclusive pedagogical materials
}

\begin{abstract}
Brazilian public policies in recent decades have promoted new arrangements in educational institutions aiming at effective inclusion of people with disabilities. This article aims to describe the experience of developing didactic materials for the inclusion of a Deaf person in a higher education institution. We are interested in reflecting on the reflexivity and conflicts involving the distinct points of view of the professionals from different areas of knowledge working at the Distance Learning Unit in the process of preparing those materials, and the institutional actions confirming this conjecture. We accessed the agents involved through the methodology of mapping social networks, and we point out the main guiding and transforming elements of this process. We understand that public policies are central to generate opportunities for social change, and we also observed the complexity in delimiting and implementing actions to meet current social heterogeneity, while the transformations this collective action provoked went beyond the objectives it explicitly aimed at.
\end{abstract}

Keywords: public policy, higher education, social inclusion, deaf people, Brazil
Volume 5 Issue 3 - 2020

\author{
Ana Luisa Borba Gediel,' Victor Luiz Alves \\ Mourão, ${ }^{2}$ Isabela Martins Miranda ${ }^{3}$ \\ 'Anthropologist \& Professor, Department of Languages and \\ Literature, Universidade Federal de Viçosa, Brazil \\ ${ }^{2}$ ssociate Professor, Department of Social Sciences, Universidade \\ Federal de Viçosa, Brazil \\ ${ }^{3}$ Trilingual Executive Secretariat, Universidade Federal de Viçosa, \\ Brazil
}

Correspondence: Ana Luisa Borba Gediel,Anthropologist \& Professor, Department of Languages and Literature, Universidade Federal de Viçosa, Brazil, Email ana.gedielufv@gmail.com

Received: June 18,2020 | Published: June 29, 2020

\section{Introduction}

The history of public policies aiming at including minorities groups shows that despite the advances since the Constitution of 1988, there is still much to be done. Considering the economic and distributive spheres, social inequality is a historical and negatively notorious characteristic of Brazilian society, even with the recent decrease in income disparity. ${ }^{1}$ Furthermore, in the last decades, there have also been advances in the expansion of policies that recognize the existing diversity in Brazilian society. ${ }^{1,2,3}$ Some of these policies play a leading role in the scenario of changes in the educational field involving the education of the Deaf. More specifically, we can cite Federal Law $10.436 / 2002$, on the Brazilian Sign Language (Libras). This law recognizes it as a legal mean of communication and expression. Decree No. 5.626/2005, which regulates the aforementioned law, establishes that federal educational institutions must offer the means for communication, information, and education to the Deaf, ensuring their inclusion, establishing Libras as a compulsory subject in undergraduate teaching courses. Additionally, Federal Law 13.146 establishes the Statute of Persons with Disabilities, aiming to ensure the exercise of the freedoms and rights of those with disabilities and their social inclusion. Subsequently, in 2015, Federal Law 13.146/2015, also known as the Law on Inclusion, was enacted to ensure and promote equality. Finally, we highlight Federal Law 13.409/2016, which institute a quota system for people with disabilities in Brazilian Federal Universities, ensuring their access to higher education.

This new scenario has pressured institutions for a set of new arrangements to adapt spaces and processes to include those with disabilities in higher education. In general, the focus of discussions

${ }^{1}$ This article a product of an investigation conducted with financial support from the Capes Foundation and Federal University of Viçosa. This is the English version of the article previously published in Portuguese in Anuário Antropológico, vol. 44, n. 1, in 2019. The authors would like to thank Anuário's editors for allowing this publication. had previously been on teacher training, on curriculum and physical structure adaptations in elementary educational institutions. However, the need for methodological changes and teacher training became central as these people started enrolling in higher education institutions. Those debates, likewise, previously characterized as a field of theoretical discussions and initial training for future action involving inclusion becomes subject to the immediate need for adaptations towards inclusion. In this article, we present some reflections regarding the experience of a higher education institution in Zona da Mata, a region in the state of Minas Gerais, Brazil, where certain strategies were used for the integration and maintenance of Deaf students in courses on different areas of knowledge. Due to the focus of this research and our position given the different discussions in the field of Disability studies, Deafness, and Deaf Movements, we use the term Deaf with capital ' $D$ ', according to a convention established by a group of Deaf leaders engaged in the academy. This identification refers, in particular, to groups of deaf people who use Libras as their first language and use it as a political, cultural and identity-based means of recognition. ${ }^{4}$ In this study, Deaf - as opposed to deaf - is defined as an emic category. That is, we use this nomenclature as established and considered by the subjects themselves.

The initial idea for this research focused on mapping technologies being used to promote the educational process regarding Libras in the institution. This focus was due to the fact that the institution is recognized for its investment in Information and Communication Technologies (ICT), understood as a set of technological resources which, when integrated, can provide autonomy and/or communication of various types of existing processes in teaching and scientific research, mediating informational and communicative processes. ${ }^{5}$ To find the professionals elaborating the ICTs in the institution, we conducted a mapping through contact networks. ${ }^{6}$ Based on this methodology, we observed the relations established among these people and verified their ability of agency and influence on this system. 
Throughout the mapping process, we were confronted with a project aimed at creating bilingual (Libras/Portuguese) teaching materials, focused in one of the undergraduate courses in the institution, which became the focus of our analysis. We started, then, monitoring the processes of identifying the needs of the student, the organization of professors, managers, technical staff and institutional space to establish the practices in order to respond to these needs.

During the mapping and contact with the professionals involved in the elaboration of inclusive ICTs, we have also identified and monitored the construction of didactic materials, which began to be developed specifically for the classes for one Deaf student. Such project began to play a key role in the context of developing technologies for inclusion in the institution, and from then on, our attention was driven to this process. The creation of the so-called "signed classes" emerged from an interdisciplinary group which developed a project aiming to create ways to support that student on his progress throughout the courses taken in higher education. This has also allowed us to observe the conflicts and stigmatization situations the subjects went through. ${ }^{7}$ In this context, we describe the agents involved in the actions that were developed, the dialogues to meet the needs arising from public policies, and the real situation of a Deaf student entering the institution.

\section{Approaching the subjects: impressions from the field}

The initial outcomes of the project and the description of the perspectives permeating the field were based on participant observation, field notes, and diaries. ${ }^{8}$ By monitoring the actions involving ICT in the Higher Education Institution investigated, we began to visualize different perspectives concerning the formulation and execution of inclusive public policies. The first contact with the research interlocutors occurred in mid-2016, with the mapping of those professors and managers working on projects and activities aimed at using ICT in the institution. As stated by Barnes, ${ }^{6}$ in order to map networks, the first contact was made with the outreach project manager of the Institution, who had a broad perspective of all the initiatives brought forward by this investigation. In this way, we found the projects being developed and the sectors or departments in which they were concentrated, in addition to understanding the links among them. Such contact enabled us to discover the units of the institution involved with the topic of the research. The person in charge mentioned several others developing these materials in the units of Distance Learning, Languages, Computer Science, the Accessibility Sector, as well as their representatives. Then, a contact network was created, and each of the interviewees appointed other influential professionals, who could enrich our research. In this process, the contact network was consolidated. However, we restricted here our data and network to the Distance Learning Unit, since it is the only sector of the institution that produces didactic materials to support the education of deaf students. Therefore, the research collaborators are shown in the chart that follows (Table 1).

For ethical reasons, the names of the people, the sectors and the institution were preserved. As we mapped and met them, we named the women "Maria" and the men "João," adding a random second name with the initial letter, in alphabetical order, according to the order they appeared in the mapping. Regarding educational background, we have an interdisciplinary team: John Daniel has a training focused on the area of Computer Science; John Edward has a degree in Communication; John Phillip in Social Sciences though he is the only one with experience and actually working with Libras; and Maria Beatrice has a background in Distance Learning. Thus, three of the four collaborators in the research come from the field of Social and Human Sciences. None of them is Deaf. After establishing the network, we moved to the second stage of the research, interviewing the members of the teams responsible for the material development. All interviews were semi-structured, ${ }^{9}$ and the participants signed the Informed Consent Form on the confidentiality of the research. ${ }^{2}$ From the interviews, we were able to know more about each project mentioned participant observation and the monitoring of some actions led us to a specific project aimed at a Deaf student, once the informants themselves were focused on this project that intended to create a version of video lectures for "signed classes". These video lectures serve as a tool to deliver didactic content in video-class format, used in the institution to provide the content for the distance learning courses. Thus, their adaptation for "signed classes" would enable that Deaf student who had enrolled at the institution should understand class content.

Table I Identifying the Interviewees

\begin{tabular}{ll}
\hline Name & Position in the distance learning unit \\
\hline John Daniel & staff member \\
John Edward & staff member \\
John Phillip & staff member - intern \\
Maria Beatrice & director \\
\hline
\end{tabular}

\section{The project to create didactic materials and autochthonous reflexion}

Deaf students' university enrolment has led to classroom pedagogical adaptations, the hirement of agents with specific educational and linguistic knowledge, as well as exchange of knowledge. Santos ${ }^{10}$ presents a panorama of researches on the process of inclusion in higher education, which indicates that the number of deaf people enrolled remains small. The researcher also argues that there is little change or adaptation in professors' approaches in order to meet Deaf students' needs. Hence, the importance of professional Sign Language interpreters - and their work on the linguistic mediation - during classes in order to achieve those needs. In this context, there have been certain institutional initiatives, such as the project before mentioned. It was conceived to meet the needs of a Deaf student, John Phillip, who required didactic materials for his studies. Although the university offered interpreters for his classes, out-of-class studies hours, autonomously, raised issues that were not identified before, referred retrospectively as "drama", as one of our interviewees explains in the excerpt that follows "Having the interpreter only in the classroom was not enough because all interaction in Libras is restricted to the classroom. If the Deaf wanted to review the [didatic] material, this would not be possible in his language, without the interpreter's mediation, which was [restricted to] the classroom [situation]. What about outside the classroom?"

Concerned with John Phillip's learning specificities a roll of efforts was put forward by Institution. He described that the second largest administrative body of the institution, the exact sciences undergraduate course coordination, professors from different

${ }^{2}$ The research project was submitted to and approved by the Brazilian Research Ethics Committee. CAEE: 81077517.6.0000.5153. 
departments, and the institution's accessibility sector all contacted the Distance Learning Unit in order to produce materials capable of meeting such needs. Initially, due to the lack of familiarity within the group of professionals with the linguistic specificity of the Deaf subject, for whom Libras was the first language and Portuguese the second, the professors of the exact sciences and the technology team thought that adding portuguese subtitles to the video lectures would suffice. They estimated that the materials would be ready for use within a few months. However, once the activities started that lack of knowledge regarding both the cultural and the linguistic specificities of the Deaf were the first obstacles they recognized. As Maria Beatrice, director of the Unit explains: "a project that at first seemed simple, just make a video lecture that meet his needs, turned out to be actually to be much more complex". In other words, the difficulties of carrying out the project were underestimated since there was little understanding on the "complexity" of Libras and the way the Deaf interacts, communicates, and learns, according to the staff members themselves. That moment of understanding and awareness was permeated by several characteristics similar to those pointed out in Goffman's studies, ${ }^{7}$ regarding a normal-stigmatized situation: perplexity, discomfort, and anxiety. But, it was also when the group started identifying the need for a set of actions, which were not explicit in the legislation, and had to be articulated in an interdisciplinary way. According to Maria Beatrice: [...] it is a different challenge because they are from different areas and different people, which takes us a little out of the comfort zone, not working on things that you master in the day-to-day routine, and in the end, it affects something that is already consolidated. So, you have to investigate, you have to study, then you realize, "ah, I do not have that competence nor that skill", I need to identify people to come and join me help this group [...] (emphasis added)

Preparing the "signed classes" began with a set of pragmatic issues that needed to be addressed in order to continue the idea proposed. It was necessary to organize a work team, draw up a training project for those involved in the execution, and plan the articulation of the different areas that would act collaboratively. This organizational effort had to go beyond that specific case, being in accordance with the demands involving the scope of inclusive public policies. Maria Beatrice also reports that, after understanding the initially underestimated difficulties, the group needed "to hire someone who knew Libras to join our trainees. We had to work with trainees focused on this area, with partnerships or more connected with the Sign Language interpreters [...]"

The perception of the lack of expertise, knowledge and accumulated skills to accomplish the task led to the search for more members for the team. This was when John Phillip, a trainee familiar with Libras, was hired to join the team responsible for producing the material. From that point on, the team organization, distribution of activities and responsibilities, and the very products of the project were reformulated. This process led to some collective reflection from which three issues emerged. First, the need to reorganize the didactic material in a presentation compatible with the specificities of the Deaf student's mode of communication and learning, using Libras and synonyms for some technical vocabulary through classifiers ${ }^{3}$ and explanations of the concept. ${ }^{11}$ Second, Libras, as a visual language, requires the use of images associated with concepts to bring the explanation to the universe of the Deaf student: illustrative images

${ }^{3}$ Classifiers are constituents of the native lexicon of Libras, in which hand configurations and orientation are important elements exercising a descriptive function, helping qualify and signify what is being expressed. are central to understanding; Finally, there was a lack of translated concepts from the exact sciences to Libras. Based on the team's findings, not only subtitling, nor simple interpretation of content for Libras using the same PowerPoint slides, previously created by the professors for the classes, would ensure the student's access to the knowledge being taught in the different courses he was enrolled. It was necessary to restructure the content didactically, adapting it to the three issues mentioned in the previous paragraph. This also demonstrated the need to create a specific glossary for the area if the material were to be considered inclusive and didactically effective. All of these linguistic, conceptual and methodological factors arise in a complex context, where team members have different perspectives on the subject, on the specificities of the Deaf person, and the actions necessary for complying with the related public policies.

The project was then directed at being able to train the team in the process of reformulating both the team and routines of activities, to only later deal with the challenge of creating didactic material for the Deaf, and with trainings regarding the learning and interaction modes of Deaf people. We believe this process permeates the execution of public policies in the sense of locating what is transcendent; complexifying what is homogeneous - avoiding falling into the selfcongratulatory conception of the official texts in order to develop a perspective that captures "ethno political practices ensuring civil rights". ${ }^{12}$ These practices involving subjects, objects, discourses, languages and networks need to be mobilized to achieve inclusive public policy goals.

\section{Mediated awareness}

Along the lines of the first reorganization of the team, the intern would be responsible for Libras-related activities in the production of the didactic material. However, his actual practice went beyond this initially assigned function, incorporating pragmatically the position of project general activities coordinator, also responsible for presenting Deaf culture to the lay members of the project, and mobilizing the various groups within the project. John Phillip recalls this initial moment of his participation in the project:

"I joined the [Distance Learning Unit] in May [and] I started the internship here so that the material could be ready by August [...] One of the first things I tried to find out and do was: let's organize a team, [but] to organize this team there was not even a project [...]. Everything was disorganized [...] My testimony is a bit critical because nothing was planned, it was like this, the need arose and 'oh': 'we need material for the coming semester'."

Once again, the lack of skills to carry out the project within the deadline became explicit. Since the 1990s, with demands from Deaf movements, the involvement of the academy, and the passing of legal documents, there has also been an interdisciplinary construction of the field of social actors involving Libras. A niche of activities that incorporates the language and experiences of this group of people in educational projects on teaching, research and extension ${ }^{14}$ has emerged. The participation of these subjects in the academic area, for example, influenced the very construction of meanings of the scientific categories that are being created in Libras, taking into account the perspective of the Deaf movement itself. However, as stated before, in the case of producing the didactic material, there were few people who actually knew Libras. In fact, only John Phillip did. This eventually led to the reformulation of functions, and as he remembers in the following exert: 
"My role at that time was to mediate. So, I really had the role of a social scientist. I coordinated the team, the people; I called people, organized study groups, meetings, discussions on what sign language were discussions on how to use technology. There was even a text, which people discussed, by Marianne Stumpf, a Deaf expert in Sign Language. And, then, we discussed those texts, and I was responsible for producing the reports. So, I would always produce a report and send it to the group and coordinate: "People, let's get together" [and schedule the gatterings]. So, that was my role, to bring the interpreters [inside the project]. Then, the interpreters began to attend the meetings. There were always one or two interpreters [from the accessibility sector]. The Deaf, [I've also] managed to articulate with them. I brought the Deaf student closer to the team, so he could also participate in the process at the beginning, on the first semester."

John Phillip took over as the person who, besides having a fundamental knowledge of the language, goes beyond this ability, acting mainly as a mediator for culture, language, diverse social practices and the team, in order to enable a collective production of the didactic materials. In addition to that, for two months, he organized and promoted a study group for the awareness of the language and deafness, composed of staff from the unit, interns from the exact sciences undergraduate course, interpreters working for the accessibility sector, and the Deaf student. At first a Sign Language interpreter he became a culture mediator promoting reflection on different ways of being and learning, and improving the expertise related to the didactic material production. Here, the selfperception of this scientist is close to the established discussion of a double hermeneutics that enables the presentation, translation, and communication of networks of meanings, which belong to certain contexts of social life, to other people who do not have access to them. ${ }^{17}$ In this way, the intern undertook a critical and sociological analysis, and, consequently, provoked social transformations towards greater reflection. John Phillip took over as the person who, besides having a fundamental knowledge of the language, goes beyond this ability, acting mainly as a mediator for culture, language, diverse social practices and the team, in order to enable a collective production of the didactic materials. From another point of view, it is possible to understand the different views of participants in the project, the conceptions regarding the Deaf movement and the spaces occupied by the language and its interlocutors. John Phillip disagrees with the category disability, which, according to Assis, ${ }^{13}$ is linked to the biomedical conception, characterizing the person based on the hearing loss. The promotion of actions was guided according to a perspective that aligns with the deaf category. ${ }^{4}$ Both positions are legitimized and assume a political character. One focused on the perspective of rehabilitation and bringing the subject closer to standardization, which can be achieved through technology such as hearing aids or cochlear implants. The other is related to the construction of identities and culture aligned with the specificity of the language. John Phillip's attitudes, besides being driven by his affinity to the deaf category, also show that the team positioned itself differently in relation to the way the target subjects of the didactic material produced were understood or they did not simply have a concept formed about such discussion yet The team's interactions and the process of growing closer to beliefs related to the deaf category previously obtained by John Phillip were incorporated through academic texts, videos with testimonies of Deaf people describing the importance of the language in their lives, and the presentation of research leading to the understanding that the

${ }^{4}$ In the body of the text, we describe the word deaf following the specific description used by Assis, ${ }^{13}$ referring to the categories disabled and deaf. didactic materials prepared with the use of the Libras and the imagery support extended the grasp of knowledge of the Deaf people using that language as their main mean of communication.

Aligned with these activities of studying and introducing the Deaf culture, an event held by the National Institute of Education of the Deaf (INES) served as an opportunity to staff members. Part of the team got to know one of the places considered an icon to the Deaf movement, according to the perspective John Phillip had presented to the group. At this event, staff members made a presentation about the project and also visited TV INES (INES television channel), specialized in producing multimedia materials similar to the university project.

Maria Beatrice reported that after the visit to the institution, there was greater integration of the group and a better understanding of the focus for the real needs in developing these activities, as she described: below: "The visits to INES formed a large group here [at the Distance Learning Unit] trying to get to know a little more about what Libras is, trying to discover what type of didactic material would be most appropriate to serve not only the Deaf but the hearing [people] too". This led to the team's awareness and qualification of the category instituted, which evoked the discourse of diversity and the differences involving the condition of being deaf and, therefore, their needs. John Daniel recognizes the differential aspect of the Deaf way of being, departing from the negativity of the typical, common sense, medical diagnosis: "the Deaf think differently, their world is different from ours, this is not bad, it's just different. We have to understand this". In retrospect, he can also identify the project's main initial problem, related to the lack of knowledge about the way the Deaf interacts and learns: "The main difficulty, at first, was to understand the target audience because we are not Deaf, and we do not have contact with Deaf people all the time here".

And the Deaf way of being, according to the interviewees, is understood as having a different, specific and distinct language, and what poses problems in the educational and communicational scopes. In the biomedical sense of disability, only sensorial, physiological and/or cognitive limitations are considered in relation to default hearing condition. Conversely, in the sense of difference, built within the work team, this condition is constructed based on the elaborations of the group itself, which seeks cultural identification linked to the linguistic question, from an emic perspective. The Deaf construct themselves as a minority group to claim social and educational rights. As mentioned by Carniel, ${ }^{16}$ the field of education becomes a space for constructing the meaning of the policies being implemented, which are authorized following the directives adopted by the State. However, this field is fruitful for power struggles through established practices in institutions, which enable pedagogical invention, according to the categories and beliefs appropriated by the agents involved. This is evident in the discourse of the research collaborators when the group positions itself politically in the face of the debate on deafness, assuming the perspective of its linguistic specificity, not treated as a disability but as a difference. Taking this bias into account, the Deaf form groups and interact in associations, strengthening ideological and political positions, and calling for visibility, accessibility, and inclusion. Thus, this perspective posits that Sign Language defies the socially accepted patterns, despite having significant meaning for the group of Deaf people who use it with a strong role of demarking the culture felt and expressed corporally.

When we consider the categories of "normality" and "abnormality" defined by Michael Foucault, ${ }^{18}$ the Deaf can be seen as "abnormal", 
just as all the other people the author mentions been outside the standards of civil or religious rights. Individuals described by the author, such as those deformed by illness or differing from the "normal" legitimized social patterns, were not foreseen neither by the law nor by the religion, which resulted in a constraint within the social decision-making and meaning-definig processes. Even today, we realize that, although there have been changes in legislation, the problem of how to deal with these people and include them in different spaces remains. John Daniel states that in order to produce the didactic material, it is necessary "to comprehend the importance of valuing Deaf culture [...]. Because people think Deaf people know Portuguese fluently, people do not know that their first language is Libras. A lot of people do not even know that Libras is an official language in Brazil and it's their second language". Moreover, when discussing the specifics of the Deaf way of communicating and the problem of producing didactic material for this audience. Adding to that, John Edward makes the following reflection: "you have to be aware, trying to put yourself in their place to see if you could really understand that". John Phillip reinforces this understanding of the communicational-linguistic specificity of the Deaf and the impact of this consensus when producing didactic materials:

"It is as if it was his second language, and not his first. And that's where the problems begin, [...] which problem? That it is another language, it is another linguistic modality, it is more difficult for the Deaf person to read a word in Portuguese sometimes than to see a sentence in Libras, even more for this Deaf student who had a good command of Brazilian sign language".

The specificities of Libras, a sign and imagery language, for instance, were elaborated by the team as a way of internal organization of the work when developing the didactic materials. For John Edward, "Libras is an extremely objective language. So, the Deaf need things and people to be extremely objective. If you are putting an image that is not very obvious above the message you want to send, this is not a good image. Find another that the concept is clear just as you spot it. If there is any subjectivity there, it is not very good. I prefer you try to be as direct and objective as possible."

It can be seen that what the interviewee notes as being "objectivity" could be called image concreteness: both the meaning and the significance must be concrete and visual, which differ from the way in which science, in its theoretical and abstract aspects, has specialized in developing. In the excerpts presented above, one can note the reflexive process of becoming aware of the difference denied in relation to the Deaf and of the complexity that involves communication through sign language. Glat and Pletsch ${ }^{19}$ consider that for inclusive education, adaptations alone are not enough. It is necessary to search for a new curricular conception, recognizing the specificities of these students.

Awareness and learning about Deaf culture and their way of learning were essential for the entire process of constructing the didactic material. The Distance Learning Unit team concluded that the proposal of simply subtitling it would not be effective in the student learning process. On the contrary, it would be necessary to do something in this student's first language, Libras. The denaturalization of written Portuguese as the first language of tDeaf was, thus, a fundamental process for genuine awareness and transition from the initial conception of producing didactic materials aimed at the Deaf as simply subtitling available material to approaching a process involving the translation/interpretation of the didactic content of the courses. This added a degree of complexity to the process as initially envisaged, which led to redesigning the project, in addition to the perception of a number of issues that had to be addressed. Here, we also notice that, in consonance with other researches, the team members producing the didactic material function as thinking and reflexive "intermediaries". They began constructing bridges enabling not only the execution of their restricted activity but also more broadly discussions on the place and access to citizenship, and recognition of those who are their objects/subjects of action. ${ }^{12}$

\section{Developing the methodology for creating accessible didactic material}

A great challenge was creating a methodology to develop accessible didactic material. The unit already had several models for the elaboration of didactic material, but none was able to provide accessibility to the Deaf. It is when the aforementioned visit to INES was essential to ascertaining the methodologies used in creating accessible materials in Libras, as explicitly stated by John Daniel: "What we noticed there [TV INES] is that there may even be methodologies, but there are several ways to do it and each place has its own way. And this way comes from the particularity of the team that they have, because the ideal in such cases is that they have Deaf people on the team, which they have. At TV INES there are several ways to design the same product. For instance, there is a Deaf who prefers using a computer camera, he takes the text in Portuguese and then signs it, and then he sends it to his Deaf colleague for a review. Finally then he sends it to the interpreter. On the other hand, there are some who prefer when the interpreter works the text, and only then the Deaf analyzes the video. There, at the TV, there are several Deaf, many hearing, and multiple interpreters. But all of them have different ways of working on the same material, and different methods to produce a video at the end. It depends on [the composition of] the team."

The reflexive process helped demonstrate that the methodology and technical construction of the materials are related to the diverse social composition of the team focused on this objective. That is, the technogram (a complex of techniques, technologies, materials, equipment, and products) is correlated with the sociogram (a complex of people, technicians, professors, students, among others) enlisted to construct accessible learning materials. ${ }^{20}$ It is this correlation between the specificity of the team and the specific technological composition that promotes a particular type of methodological resolution for the quest of creating didactic content. As previously mentioned, another issue the project faced was the lack of specific signs for the technical jargon of the area of knowledge. Several technical terms had no signs, which made the job more difficult. This arises, in part, from other specificities of Libras. It has always been considered a marginalized language, especially as it is a visual one and which began to gain prominence only in the 21 st century. It is important to emphasize that it is the language of the Deaf community and they can express themselves just like the hearing can, even regarding abstract concepts. ${ }^{21}$ It has its own grammar, and its variations are given through the configuration of hands, facial, and corporal expressions, all of which provide meaning to the language. ${ }^{11}$ The language is still in the process of recognition and lexicon expansion. Furthermore, sign language studies in Brazil are very recent, which leads to a lack of words, concepts, and expressions, especially in areas not yet explored, such as technical terms in exact sciences.

To meet this challenge, a training based on the processes of 
creating Libras signs was organized for the team members. A key source of information was a Deaf community on Facebook in which there was collective sign-creating work. The team was also supported by a Deaf person, who would benefit from that material, to assist in the process of creating the signs and in the evaluative feedback from other Deaf people. First, he joined a group of Deaf who took courses in the field of the exact sciences in Brazil based on interactive digital media, to gain knowledge and exchange the signs being used and created. Subsequently, considering that a substantial amount of concepts still had no signs designated, the Deaf student, together with the didactic material creation team, began mapping the specific signs and those that had not yet been registered through signs agreed by the Deaf participants in the academic context and in the Deaf leadership movements. After the preliminary elaboration of a sign for one concept performed by the interpreters and the Deaf, together with the monitor from the area, this sign was sent to the Deaf leaders residing in different regions of the country, so that there could be an evaluation of this new sign. As John Phillip explains, "as he [the Deaf student] and other Deaf people created a Facebook group of [exact sciences] to propose signs for concepts that did not exist, [...] we studied how the interaction on Facebook worked". According to him, the interaction of the Deaf people through online interaction media for cataloging and constituting the specific signs of a particular academic area helped to deepen reflection on the Deaf way of learning.

At this stage, the idea was to create the signs that did not exist yet, with a method involving several members (professors, the intern, Deaf subjects, and interpreters). There were several attempts to create these signs, and new obstacles arose. John Edward explains that "The initial idea was that for every term [in Portuguese] that has no sign [in Libras], this sign would be created. The problem is that this whole process takes a lot of time. You do not simply create a sign like 'ah, I created a sign, and here it is'. No, you have to check it with the Deaf, the interpreter, etc." John Daniel agrees, after realizing the cultural aspect and the recognition in the process of creating these terms, that the signs must be created and accepted by the Deaf community. He also observes that they were trapped once again since as there were several "courses that have many technical terms of their own [and] that do not [have] any signs designated, we again came across another problem in that regard." There was thus a double problem identified:

the time-consuming process of creating the signs, involving several phases and different people;

the process of acceptance by the Deaf community, which might not adopt (and therefore reject) the sign created.

A moment of creativity and acceptance on the part of the Deaf community was needed. As there was a stipulated short-term deadline for delivering the materials, such procedure was although more effective in the context of communicating meanings was abandoned. The alternative found was to use the word finger spelling, illustrative images, and classifiers in order to achieve didatic exchanges. After these comings and goings, a methodology for creating materials for Deaf people known as "signed classes" was built. ${ }^{22}$ This method, which provides some steps, is an adaptation of an already existing method, video lectures, but in a signed version. Firstly, the interns and the professors together organize the course material on a PowerPoint slide. This slide is sent to the intern with knowledge of Libras, who translates the material, being reviewed by the coordinator of the accessibility sector, also fluent in Libras. Then, a gloss is added.
That is, the written transposition of the syntax of what is signed in Libras into Portuguese, with the addition of codes leading to the understanding of the grammar of Libras. ${ }^{23}$ With the aid of an audio guide, a video of the interpreter signing the gloss is made. Despite being in Libras, an audio guide is needed to instruct the interpreter in the signing and also help the editor when editing the video.

This entire materials ready, the video was edited. This phase also had to be adapted as it was noticed that the picture with the interpreter was usually very small, which made it difficult to see the details. To make this material, $1 / 4$ of the screen was dedicated to the interpretation in Libras. The video framing was adapted accordingly. In order to allow necessary movement for Sign Language interpretation was defined using the distance and the space of one foot above the head; and, on the sides, the distance of the open elbows forming two triangles with the hands folded in front of the chest.

\section{Consequences of the project: unexpected effects}

This entire complex plot carried forward by the need for didactic materials accessible to the Deaf student had a series of unexpected effects: the dissemination of knowledge about Libras and the cultural and cognitive specificities of the Deaf, the need for specialized training in higher education, and intensified discussions on the production of accessible didactic materials. This generated a process of awareness and rectification of stigmatized "rationalizations" that Goffman ${ }^{7}$ identifies. We noticed, then, a change in the position and perspective of the technicians themselves, who have gradually come to understand the situation of the Deaf, as John Edward observes: "Another thing that I found interesting and very important: that [the project] even created a mismatch between us and the professors who create the content. We had the study group and were spending time with the Deaf, so we understood how they act and learn, which is totally different from us." On the one hand, what John Edward identifies as a mismatch refers to a conflicting tension among the professors from the institution (considered to be experts in the area in which they teach) and the members of the team producing the accessible didactic material. Such conflict arose while going through the process of becoming aware of the specificity of the Deaf way of being and learning, the team called into question the full capacity of the professors to carry out their pedagogical work. On the other hand, there is this potential for the multiplication of the wise, those who have had experiences that enable them to identify the difficulties the Deaf are experiencing and to recognize this community as endowed with specificities and rights, as well as valued professional and social skills. John Daniel expresses this learning well when he says that: "the greatest advance [systematic production of accessible didactic material and, consequently, effective social inclusion] here [at the Institution] would be having the Deaf work here with us. Working here, both in our text and in textual production sectors. A Deaf person could really help there, you know what I mean? There would have to be a Deaf employee as part of the team because how am I going to work in a second language, in another language, without having a person who is native in that language? There must be one.."

It is in this dynamic process of interaction that reflexive processes and the permeating conflicts become relevant, revealing that the "practices of constructing citizenship"12 are far from consensual, being rather reluctant daily and reflexive practice which is more of a Simmelian association than a static realization of an ideal citizenship 
determined by law. It is in this sense that we agree with Simmel when he states that conflicts are indispensable for group cohesion, as it is a condition for maintaining the process that unifies and at the same time transforms social groups. It works as both a disintegrating and an integrating force on the group. ${ }^{24}$ In the case here analyzed, tension appears in the team's process of absorbing knowledge of Deaf Culture and their way of being and communicating. This dislocates them from the typical common sense position (of the "normal") approaching the position of the "wise", nevertheless creating a possible bridge of social relations between "normal" and "stigmatized" people. Such overlapping "antitheses and syntheses", ${ }^{25}$ stem from the dynamic nature of this process, which affects not only the target population of the inclusion policy, but especially those in charge of carrying out activities for this purpose. These centripetal and centrifugal forces are dynamic and guide the process of identity construction of the various groups involved. The importance of the nature of social relations in Simmel appears, in this case, as the standardized modes of stigmatized-wise-normal relations. ${ }^{26}$

Absorbing and reflecting on the questions of Deaf culture, the Deaf community, the specificities of this population and appropriate ways of creating didactic materials aimed at this group, brought together the technical and cultural competence to create not only the specific didactic materials for the courses but also to develop an appropriate methodology to develop accessible didactic materials. ${ }^{27}$.

\section{Conclusion}

We argued in this text that the implementation of public policies aimed at reducing social inequality, permeating the formal progress and legal recognition of the rights of minority groups and populations does not, by itself, solve the citizenship deficit marking our social existence. Concrete implementation of the egalitarian precepts of these policies leads us to even greater complexity in these social processes of transformation. In view of this problem, reflexive process on policy formulation and implementation experiences is fundamental not only to assessing the degree of effectiveness in its implementation, but also to draw lessons and to improve and correct their trajectories.

The analysis of the process through which a team responsible for producing accessible didactic material went through based on their own account of this experience helps us better understand the process of executing projects aiming to implement a policy of social inclusion and also of diversity recognition within a higher education institution. We concluded that it is not enough that the project teams create technologies and didactic materials to promote accessibility and inclusion. It is also necessary - and this is a fundamental point - that the community of users accepts and recognizes such material as fit for its purpose. Such considerations legitimate not only the inclusion of the users in the teams creating the didactic materials for their own use but also, likewise, on the committees for formulating public policies aimed at inclusion. As Michel Callon says, the processes of conceiving and disseminating technologies are not clearly separated from each other: users of technologies are present from the initial conception process, and this never ends, even after the process of technology dissemination has become relevant. The effectiveness and efficacy of these inclusion-oriented teaching materials are not limited to technical or even pedagogical aspects. There is a fundamental social and cultural element stating that technology can only exist if it is recognized as such by its user group. What network will enable the adoption and use of these materials? Who are the people in charge of disseminating the information and skills enabling such use?
The methodological and inclusive problems were clearly apparent: the process of constructing the inclusive didactic material had to take into account the Deaf as an active part in this process in order to increase the pedagogical effectiveness of the content produced. The theme of Deaf learning, which centers on the image and on the visual configurations of their language, calls not only for sensitivity on the part of professors and those responsible for pedagogical creation. On the contrary, it demands the incorporation of the Deaf and their culture into the ways of conducting teaching/learning processes. Throughout the process, their inclusion is, at the same time, a reciprocal transformation enriching the pedagogical process by promoting reflexivity on different teaching/learning modes. Bearing in mind that it is through interaction that certain fundamental learning processes take place, we must notice that these refer to the process through which those responsible for producing materials must undergo in order to build inclusive didactic technologies. To overcome such difficulties, it was possible to demonstrate the importance of the intermediary in solving problems related to cultural diversity, in addition to revealing the unexpected effects of a policy aimed at inclusion.

It can be seen, then, that at the end of the process of preparing the "signed classes", certain impacts caused by the accessibility and inclusion policy went beyond the target social group. It is Goffman's "normal" ones who underwent a process of re-situation in the world and in citizenship learning. Implementing activities for the broader inclusion policy, thus, has an unintended, albeit, desired effect of the actions promoted in its name: multiplying those capable of promoting social inclusion processes. That is what provides greater capacity to identify the central and problematic core of social inclusion policies and, therefore, propose viable solutions for a process of inclusive social transformation through pedagogical practice. It is possible to see that the discussion of the normal-stigmatized interaction situation provoked by the projects was prepared based on a reflexive process led by someone wise (someone who knew Libras and who, correspondingly had access to Deaf culture). Moreover, via collective work involving the presentation of Deaf community behaviour, he also organized the memory of this process of interaction - via reports and other textual productions - to facilitate and develop the production of accessible didactic material. Considering this, the following can be perceived: (1) the importance of an "wise" person to create bridges with the Deaf community, providing access to the information and knowledge needed to create the material; (2) the transformation of these people, while becoming aware of a "difference" that gradually ceases to be stigmatized and becomes normative, almost becoming "wise".

The process of preparing "signed classes" showed that, although there were several difficulties related to producing inclusive didactic material, there were moments of reflexive considerations about the inclusive policies, and their immersion in the educational reality. These obstacles resulted in a new perspective, rewriting trajectories, and pointing out actions that could be included. Such developments will be contextualized as a means of analysis with repercussions on the knowledge, routines, experiences, and effects constituting inclusion policies in Brazil, in higher education. Furthermore, it can be argued that public policies of inclusion teach more those who apparently position themselves in the "established" point of social normalcy when they realize that there is much more to be learned about themselves from those who are usually in a subaltern situation in our society. 


\section{Acknowledgments}

None.

\section{Funding}

None.

\section{Conflicts of interest}

Author declares that there is no conflict of interest.

\section{References}

1. Dedecca Claudio S. The drop in current income inequality and the share of $1 \%$ of higher income households, 2000-2010. Revista de Economia Política. 2014;34(2): 249-265.

2. Fraser Nancy, Honneth Axel. Redistribution or recognition? A politicalphilosophical exchange. New York: Verso. 2003.

3. Fraser Nancy. From redistribution to recognition? Dilemmas of justice in a "post-socialist" era. Field Notebooks. 2006;14/15:231-239.

4. Padden Carol, Humphries Tom. Inside Deaf Culture. Cambridge, Massachusetts: Harvard University Press; 2006.

5. Da Silva Marilda. Complexity of teacher training: theoretical knowledge and practical knowledge. São Paulo: Editora UNESP; 2009.

6. Barnes John A. Social Networks and Political Process in JA Barnes. In: Feldman-Bianco Bela, editor. Anthropology of contemporary societies, São Paulo: Global; 1987. p. 159-193.

7. Goffman Erving. Stigma: notes on the manipulation of deteriorated identity. 4th ed, Rio de Janeiro: LTC; 2012.

8. Cardoso De Oliveira Roberto. Anthropologist's Work: Looking, Listening, Writing. Revista de Antropologia. 1996;39(1):13-37.

9. Triviños Augusto NS. Introduction to Social Science Research: Qualitative Research in Education - Positivism, Phenomenology, Marxism. São Paulo: Atlas; 1987.

10. Santos Emmanuelle F. Weaving readings in Libras research: meanings attributed to its teaching in higher education. In: Almeida Wolney G, editor. Deaf education: training, strategies and teaching practice. Ilhéus, BA: Editus; 2015. p. 67-91.

11. Quadros Ronice M, Karnopp Lodenir. Brazilian Sign Language: linguistic studies. Porto Alegre: Artmed; 2004.

12. Claudia Fonseca, Denise F Jardim, Patrice Schuch, et al. Presentation. Horizontes Antropológicos. 2016;22(46):9-34.
13. Assis Silva César A. Between disability and culture: ethnographic analysis of missionary activities with deaf people. Doctoral Thesis, São Paulo: FFLCH/USP; 2011

14. Brito Fábio BD. The deaf movement in brazil: the search for rights Journal of Research in Special Educational Needs. 2016;16:766-769.

15. Callon Michel. Technological Conception and Adoption Network: Lessons for the CTA Practitioner. In: RIP Arie, MISA Thomas J, et al. Managing Technology in Society. London: New York, Pinter; 1995. p. 307-330.

16. Carniel Fagner. The (pedagogical) invention of deafness: on the state management of special education in the first decade of the 21st century. Florianópolis: Federal University of Santa Catarina, Center for Philosophy and Human Sciences; 2013.

17. Giddens Anthony. The Constitution of the Company. São Paulo: Martins Fontes; 2007.

18. Foucault Michael. The freaks. São Paulo: Martins Fontes; 2001.

19. Glat Rosana, Pletsh Márcia D. The role of the University in the context of Inclusive Education policy: reflections on the training of human resources and the production of knowledge. Revista Educação Especial. 2010;23(38):345-356.

20. Latour Bruno. Science in Action. How to follow scientists and engineers across society. São Paulo: Editora Unesp; 2000.

21. Gesser Audrei. LIBRAS? What language is this ?: beliefs and prejudices around sign language and deaf reality. São Paulo: Parábola; 2009.

22. Souza André LSD, Júnior José T. The Use of Technologies (ICT) in the Production of Libras / Português Bilingual Teaching Material. Revista Fórum (INES). 2016;33:92-109.

23. Ferreira-Brito Lucinda. For a Grammar of Sign Languages. Rio de Janeiro: Tempo Brasileiro; 1995.

24. Simmel Georg. The sociological nature of the conflict. In: Moraes Filho Evaristo, editor. Georg Simmel: sociologia. São Paulo: Ática. 1983a. p. $122-134$.

25. Simmel Georg. Conflict and group structure. In: Moraes Filho Evaristo, editor. Georg Simmel: sociologia. São Paulo: Ática. 1983c. p. 150-164

26. Simmel Georg. How social forms remain. In: Moraes Filho Evaristo, editor. Georg Simmel: sociologia. São Paulo: Ática. 1983b. p. 46-58.

27. Imbernón Francisco. Teacher training and professional: formed for change and uncertainty. 7th ed. São Paulo: Cortez; 2010. 